\title{
Improved ROCOF relay for islanding detection of solar distributed generation
}

\author{
J. Rajesh Reddy, A. Pandian \\ Department of Electrical and Electronics Engineering, Koneru Lakshmaiah Education Foundation, India
}

\begin{tabular}{l} 
Article Info \\
\hline Article history: \\
Received Dec 14, 2018 \\
Revised Feb 13, 2019 \\
Accepted Feb 27, 2019 \\
\hline
\end{tabular}

\section{Keywords:}

Distributed generation Improved ROCOF Islanding detection Non detection zone Solar DG system

\footnotetext{
Corresponding Author:

J. Rajesh Reddy,

Department of Electrical and Electronics Engineering,

Koneru Lakshmaiah Education Foundation ( K L University),

Green fields, Vaddeswaram, Guntur, Andhra Pradesh, India. 522502

Email: rajeshreddy.jetty@gmail.com
}

\begin{abstract}
In recent years to meet the energy consumption demand of the world, all are working on renewable distributed generation (RDG) due to the shortage of fossil fuels. The RDG systems after integrating with grid, has a disadvantage of islanding in the power system. Islanding is caused, if the RDG is supplying power to the load connected due to failures in the grid. As per IEEE 1547 distributed generation (DG) interconnection standards, the islanding should be detected within 2 seconds after islanding. In this paper a hybrid islanding detection scheme is presented with a rate of change of frequency (ROCOF) and reactive power injection with positive feedback. It will reduce the non detection zone (NDZ) of the passive ROCOF relay to zero and can detect balanced islanding. The computer simulations are performed on MATLAB-2016. The simulation results show the effective
\end{abstract}

Copyright @ 2019 Institute of Advanced Engineering and Science. All rights reserved.

\section{INTRODUCTION}

Nowadays to meet the total energy consumption demand of the world, it is better to look towards RDG. The RDG system which is connected at the consumer level of power grid is called DG [1]. The main problem with such DG is islanding. Islanding is caused, if the RDG is supplying power to load connected due to failures in the grid [2]. The islanding is unsafe to field persons and equipments connected because the servicing persons are not mindful that the frame up is connected and supplying with DG near. The main causes of such unintentional islanding are due to the failures detected by the grid, accidental opening of circuit breaker $(\mathrm{CB})$ at the grid, intentional opening of $\mathrm{CB}$ for maintenance, human errors and an act of nature [3]. The basic grid interfacing rules listed in the Table 1, needs that it is necessary to disconnect the DG source within 2 seconds after islanding, because if the island load is more or less, then it leads to variations in the voltage, frequency, active, reactive powers outside the standards, which may hazardous to customer loads connected to it and sometimes for DG [4-6]. The islanding detection methods are classified as local and remote techniques; again the local techniques are classified as active, passive and hybrid techniques.

By injecting small disturbance at PCC for some cycles and observing the deviations in the output signal active methods will detect the islanding [7-11]. In the grid connected system, the system absorbs the local disturbance and considerable deviations are not observed. However, more deviations are observed in the output signal if the system is islanded. Active methods are more efficient than passive methods with less NDZ, but they are affecting the power quality [12-16]. The region or range of values where islanding detection method fails to detect islanding is called NDZ [17]. In passive techniques, regional parameters such as voltage, frequency, current, phase angle, THD are monitored at the PCC, if their changes are beyond a 
certain threshold level then islanding is detected [18]. The hybrid methods are the combination of both active and passive methods. When a passive method suspects islanding, active method will come into action and confirm the islanding. These methods have less NDZ than passive methods, but they degrade the power quality [19-24]. Rate of change of frequency (ROCOF) [25], [35], the rate of change of active power (ROCOAP) [26], phase angle difference [27], the rate of change of voltage (ROCOV) [28], the rate of change of reactive power ROCORP [29], over under voltage / over under frequency (OUV/OUF) [30] are some passive methods, they are suffering with the large NDZ, and fails to detect islanding at low or zero power imbalance conditions. The combination of any two passive parameters is used to reduce the NDZ, like ROCOF and output power [31], ROCOV and THD [32], ROCOV and power factor [6], [28], ROCOV and ROCOF [33], ROCOAP combination with ROCORP [34]. These methods will reduce the NDZ to less compare to single parameter passive techniques. But most of the passive methods fail to detect islanding at low or zero power imbalance conditions.

Table 1. Islanding Detection Time, Frequency and Voltage Ranges of Various Standards

\begin{tabular}{lcccc}
\hline Standard & Quality factor & Island detection time, $\mathrm{t}(\mathrm{ms})$ & Range of frequency & Voltage range \\
\hline IEEE 1547 & 1 & $\mathrm{t}<2000$ & $59.3 \leq \mathrm{f} \leq 60.5$ & $88 \% \leq \mathrm{V} \leq 110 \%$ \\
IEC 62116 & 1 & $\mathrm{t}<2000$ & $\mathrm{f}_{0}-1.5 \mathrm{~Hz} \leq \mathrm{f}_{0}+1.5 \mathrm{~Hz}$ & $85 \% \leq \mathrm{V} \leq 115 \%$ \\
Korean standards & 1 & $\mathrm{t}<500$ & $59.3 \leq \mathrm{f} \leq 60.5$ & $88 \% \leq \mathrm{V} \leq 110 \%$ \\
UL 1741 & $\leq 1.8$ & $\mathrm{t}<2000$ & Setting value & Setting value \\
VDE 0126-1-1 & 2 & $\mathrm{t}<200$ & $47.5 \mathrm{~Hz} \leq \mathrm{f} \leq 50.2 \mathrm{~Hz}$ & $80 \% \leq \mathrm{V} \leq 115 \%$ \\
IEEE 929-2000 & 2.5 & $\mathrm{t}<2000$ & $59.3 \leq \mathrm{f} \leq 60.5$ & $88 \% \leq \mathrm{V} \leq 110 \%$ \\
AS47773-2005 & 1 & $\mathrm{t}<2000$ & Setting value & Setting value \\
\hline
\end{tabular}

In this paper a hybrid islanding detection scheme is presented with ROCOF passive method and an active method of reactive power injection with positive feedback. The ROCOF passive method will suspect the islanding, when the frequency disturbance is observed. The reactive power injection based active method will confirm the islanding and non islanding events by changing the direction of injected reactive power. It will reduce the NDZ to zero and can also detect balanced islanding.

\section{TEST SYSTEM FOR ISLANDING IN DG}

The test system considered for islanding detection with proposed method is shown in Figure 1. It consists of $100 \mathrm{KW}$ solar DG, connected to the grid (3 phase voltage source) at the distribution level of the power system. The intentional islanding is developed by opening the CB at the PCC.

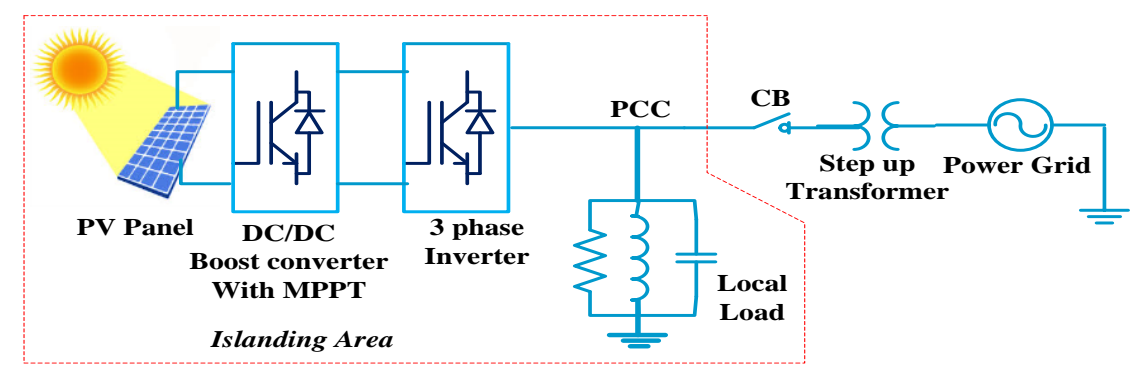

Figure1. Test system under study follows.

The step wise procedure as per IEEE 1547 standards, employed for testing the proposed method is as Step 1: $100 \mathrm{KW}$ PV system, maximum power point tracking (MPPT) boost converter, inverter, load and grid are connected as shown in Figure 1. The CB is closed and the inverter exports the power to grid at unity power factor (UPF).

Step 2: The inverter is programmed, so that it can trips the solar DG, as per IEEE 1547 voltage and frequency standards shown in Table 1.

Step 3: By opening the CB at PCC, the intentional islanding is created and the plots are recorded.

Step 4: If any frequency deviations are observed after islanding, the reactive power is injected and again its sign changed, to confirm the islanding. 


\section{ISLANDING DETECTION METHOD}

The hybrid islanding detection methods uses both the features of active and passive methods to confirm the islanding and non islanding events. The passive ROCOF method will suspects the islanding, if the ROCOF is disturbed from the study state value. The reactive power injection based active method will confirm the islanding, by injecting the reactive power.

\subsection{ROCOF passive Islanding Detection Scheme}

The passive ROCOF relay (Figure 2) will work on the equation given in (1-2). The frequency is found with three phase locked loop (PLL) from voltage signals at PCC. The effective value of ROCOF is calculated by (1), having a measurement window of $500 \mathrm{~ms}$ and the trip signals are sent to the $\mathrm{CB}$ if the calculated effective value of ROCOF ' $\beta$ ' is more than a threshold value [24], [36]. This method has advantages; it cannot trips for non islanding cases.

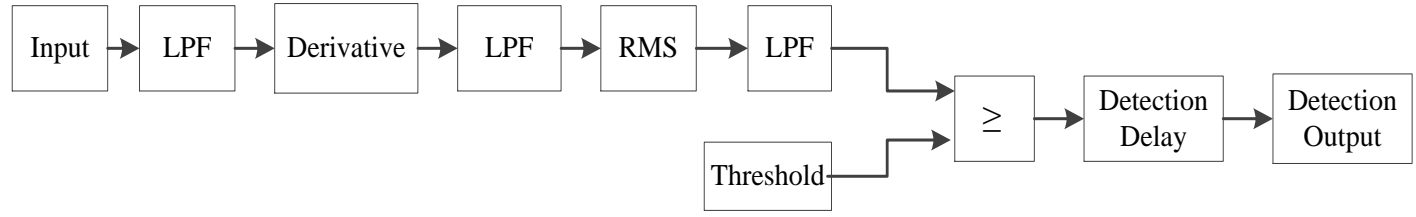

Figure 2. Passive ROCOF relay for islanding detection

$$
\mathrm{ROCOF}=\frac{1}{n} \sum_{k=1}^{n}\left|\frac{d f}{d t}(k)\right|
$$

Where, $n=\frac{\Delta t}{T_{S}}$

$\mathrm{n}=$ number of samples for a window size of $\Delta \mathrm{t}$.

$\mathrm{k}=1,2,3$ $\mathrm{n}^{\text {th }}$ sample and

$\mathrm{T}_{\mathrm{s}}=$ Sampling time

$$
\frac{d f}{d t}(k)=\frac{f\left(t_{k}\right)-f\left(t_{k}-\Delta t\right)}{\Delta t}
$$

$f\left(t_{k}\right)$ - Value of frequency at the time of $\mathrm{k}^{\text {th }}$ sample i.e. $\mathrm{t}_{\mathrm{k}}$.

$f\left(t_{k}-\Delta t\right)$ - Measured value of frequency, $\Delta \mathrm{t}$ before the $\mathrm{k}^{\text {th }}$ sample time i.e. $\mathrm{t}_{\mathrm{k}}-\Delta \mathrm{t}$.

The ROCOF relay operation depends on the imbalance between load and generation and frequency changes at PCC. But this method fails to detect balanced islanding.

\subsection{Reactive Power Injection based Active Islanding Detection Method}

When the system is changing from grid connected mode to islanding mode, the frequency deviations are occurring at PCC, depending on the shape of reactive power injection. One of the already existing methods is, injecting the discontinuous square wave of $5 \%$ rated current. This is effecting the power, power quality and reducing the power factor. To overcome these power quality issues, the reactive power is injected with $1 \%$ of rated current as a triangular wave. Hence, the injected reactive power is very small and cannot degrade the power quality [35]. The power factor at PCC is given by (3)

$$
P . f=P_{D G} / \sqrt{P_{D G}^{2}+Q_{\text {Injected }}^{2}}
$$

When the system is operating at rated power, the power factor may go down to 0.9999 , hence this reduction may be neglected. If the positive reactive power is injected, the frequency deviations will increases and if the negative reactive power is injected, the frequency deviations will decrease. 


\subsection{Proposed Hybrid ROCOF Relay for Islanding Detection}

The proposed hybrid islanding detection method uses passive ROCOF relay presented in Section 3.1 and active method presented in Section 3.2. When the CB shown in Figure 3 is closed, the test system is working in grid connected mode and if the CB is opened the test system will work in islanding condition.



Figure 3. Active and reactive powers in grid connected and islanding operation

In grid connected mode the active and reactive powers received by the load are given by (4-5)

$$
\begin{gathered}
P_{\text {Load }}=P_{D G}+\Delta P \\
Q_{\text {Load }}=Q_{D G}+\Delta Q
\end{gathered}
$$

Where $P_{\text {Load }}, Q_{\text {Load }}, P_{D G}, Q_{D G}, \Delta P$ and $\Delta Q$ are load active power, load reactive power, active power supplied by DG, reactive power supplied by DG, grid active power and grid reactive power respectively. If voltage and frequency in grid connected mode is $\mathrm{V}$ and $\mathrm{f}$, load active power (6), reactive power (7) and load impedance (8) at UPF can be written as

$$
\begin{aligned}
& P_{L}=\frac{V^{2}}{R} \\
& Q_{L}=V^{2}\left(\frac{j}{\omega L}-j \omega C\right) \\
& \left|Z_{L}\right|=\frac{V^{2}}{\left|\Delta P+P_{D G}+j \Delta Q\right|}
\end{aligned}
$$

When the CB is opened the system is in islanding condition, in islanding mode, we can write the change in voltage (9) and frequency (10) as

$$
\begin{aligned}
& V^{\prime}=\frac{V}{\sqrt{\left(1+\frac{\Delta P}{P_{D G}}\right)^{2}+\left(\frac{\Delta Q}{P_{D G}}\right)^{2}}} \\
& R \sqrt{\frac{C}{L}\left(\frac{\omega^{\prime}}{\omega}-\frac{\omega}{\omega}\right)=\frac{\Delta Q}{\Delta P+P_{D G}}}
\end{aligned}
$$

When the system is changing its state from grid connected mode to islanding state the voltage (9) and frequency (10) at PCC are changed due to small changes in active and reactive power. The proposed algorithm should be capable to sense these changes; else it leads to incorrect results. 
The proposed hybrid islanding technique uses the combined features of the passive ROCOF method and reactive power injection based active method. It identifies the small change in frequency and injects the reactive power in a suitable direction to detect islanding. To inject the reactive power in a positive or negative direction d-q reference frame controller is used, which is shown in Figure 4.

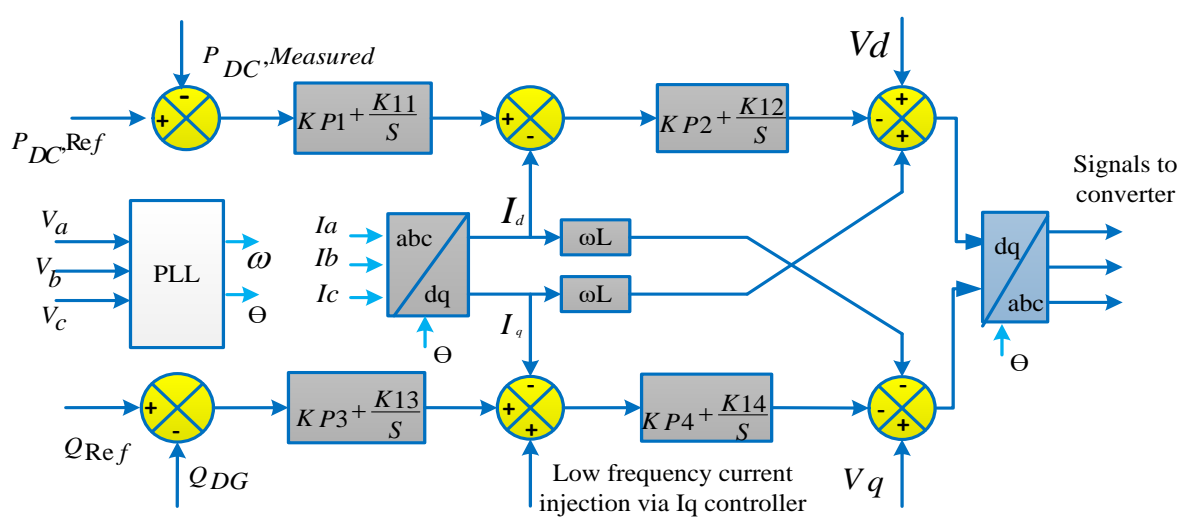

Figure 4. Controller circuit for grid integration and reactive power injection

In grid connected operation, the d-q controller [24] injects reactive power at UPF and it cannot affect the power quality. During islanding, this controller injects reactive power in the proper direction to detect islanding. Phase locked loop (PLL) is used to find the frequency changes, if the ROCOF is increasing; the controller injects the reactive power in the positive direction so that ROCOF increases at point $\mathrm{B}$, shown in Figure 5. After some delay time, at point $\mathrm{C}$, the $\mathrm{q}$ controller injects the reactive power in the reverse direction, so that ROCOF is negative and becomes zero at point $\mathrm{D}$. At point $\mathrm{D}$, the islanding is detected.

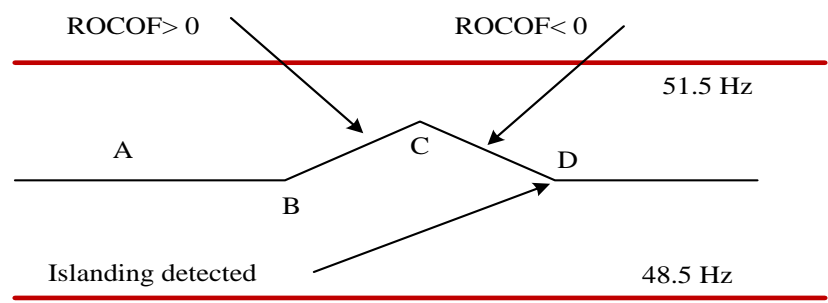

Figure 5. Proposed Hybrid islanding detection technique

The flow chart of the proposed hybrid technique is shown in Figure 6. At PCC the PLL finds the changes in frequency. If the system is in the grid connected mode, there are no changes in frequency. If the system is islanded, the frequency will change and reactive power is injected by d-q controller. If the ROCOF is increasing or decreasing, the direction of reactive power is changed. If the direction of reactive power is reversed, the ROCOF is reversed and become zero at some point (D) where islanding is detected.

The advantages of this technique are:

(a) It can detect islanding at zero power balanced islanding and ZDZ is almost zero.

(b) It cannot inject reactive power continuously, so power quality cannot be degraded.

(c) This is a simple technique and can be implemented easily with d-q controller.

(d) The reactive power required is very less compared to other active methods.

\section{COMPUTER SIMULATION RESULTS}

The test system shown in Figure 1 is simulated in MATLAB-2016a. Different cases of islanding are studied with different active and reactive powers. The proposed hybrid method detects islanding with ROCOF analysis and reactive power injection based ROCOF analysis. It is found that, the proposed method 
can detect islanding even at small or zero power balanced islanding and also works inside the conventional ROCOF relay. The computer simulations voltage, current, frequency and ROCOF of a conventional ROCOF relay are shown in Figure 7 . When the load is capacitive load, firstly negative reactive power is injected which results, decrease in ROCOF, and when it starts decreasing positive reactive power is injected which results in increase in ROCOF and islanding is detected.

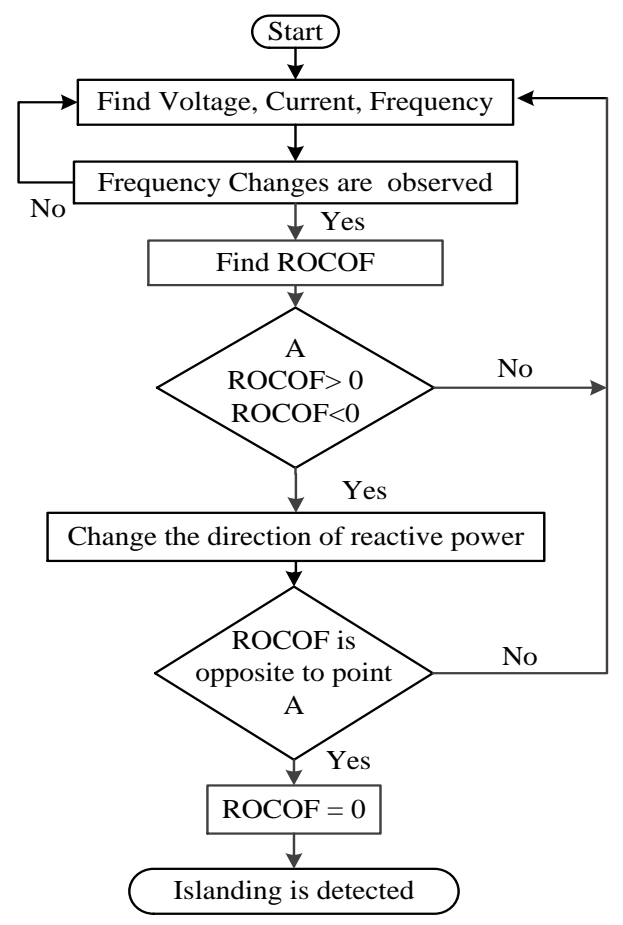

Figure 6. Flow chart of proposed hybrid islanding detection technique.
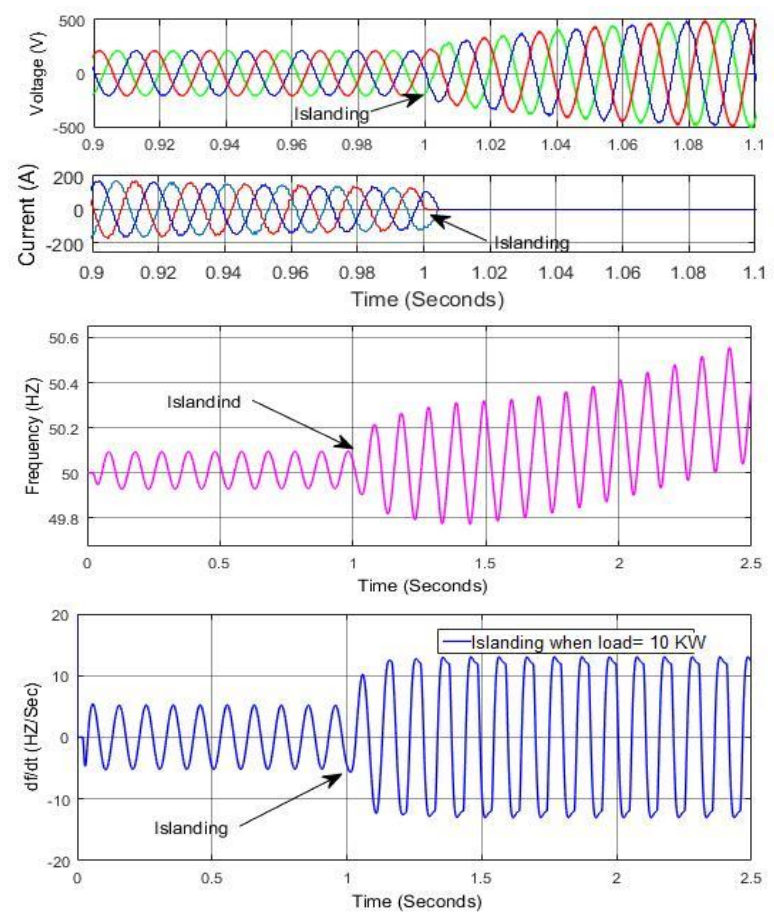

Figure 7. Simulation results of conventional ROCOF relay Voltages, Currents, Frequency and ROCOF 
Similarly Figure 8, shows the simulated results for $33 \%$ active power and $5 \%$ capacitive reactive power load. The simulation results for $66 \%$ active power and 5\% inductive load are shown in Figure 9 . When the load is inductive load, first the reactive power is injected in a positive direction, which results increase in ROCOF. When the ROCOF starts increasing, the injected reactive power is reversed, which results the ROCOF decreasing. When the ROCOF is negative the islanding is detected. Similarly the simulation results in Figure 10 are recorded for 33\% active power and 5\% inductive reactive power load. Figure 11 and 12 shows the simulation results for $66 \%$ and $100 \%$ active power load without reactive power. This result shows that an islanding can be detected with this method even at low or zero power balanced islanding.
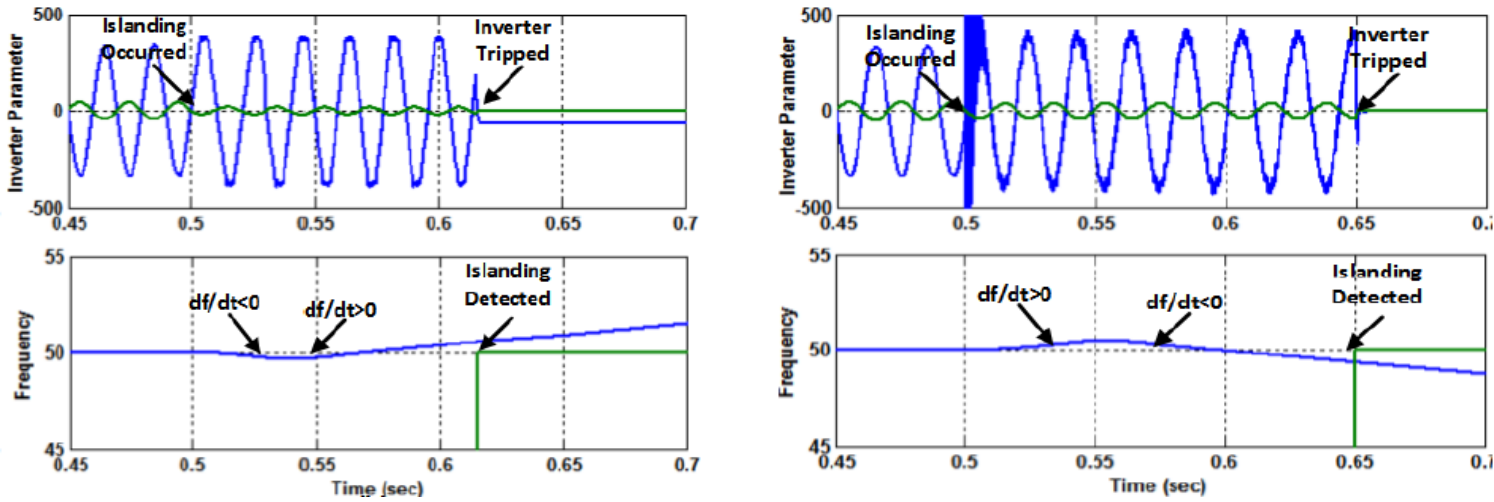

Figure 8. Computer simulation result for $33 \%$ active power and $5 \%$ capacitive reactive load

Figure 9. Computer simulations for $66 \%$ active power and $5 \%$ inductive reactive power load
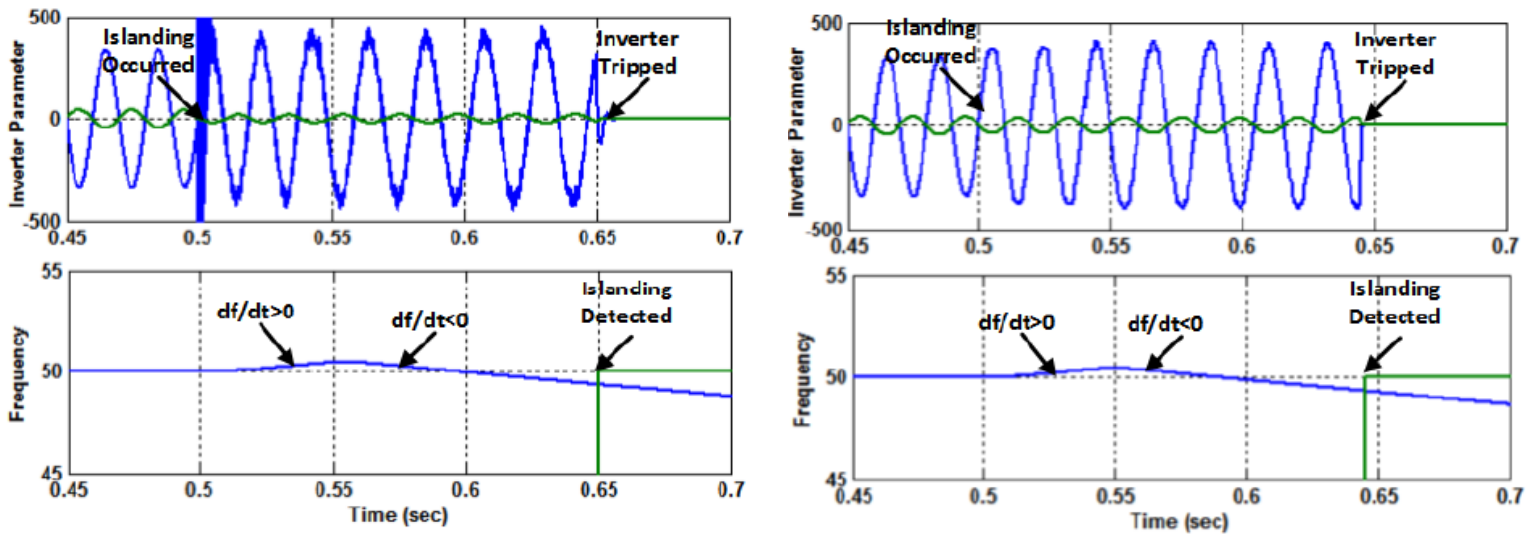

Figure 10. Computer simulations for $33 \%$ active power and $5 \%$ inductive reactive power load

Figure 11. Computer simulations for $66 \%$ active power load and zero reactive power load

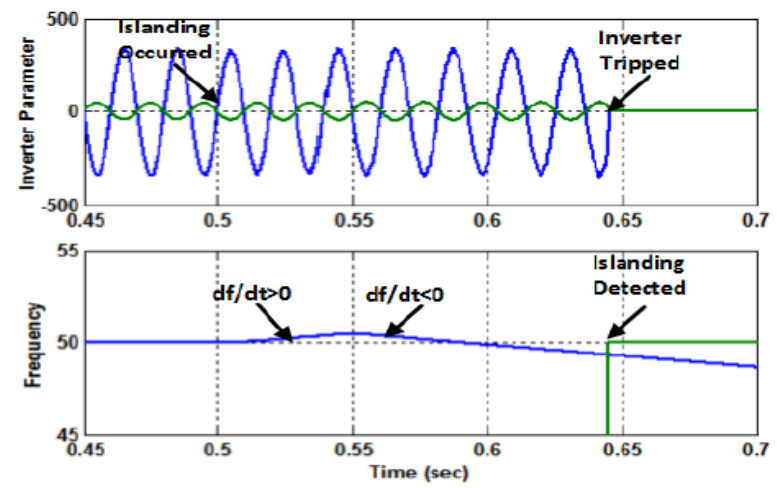

Figure 12. Computer simulations for $100 \%$ active power load and zero reactive power load 


\section{CONCLUSION}

In this paper a new hybrid passive islanding detection method is presented in grid integrated solar PV system with ROCOF analysis and reactive power injection based ROCOF analysis. When the passive ROCOF analysis identifies the changes in frequency after islanding, the islanding is confirmed by the reactive power injection based active method. For capacitive loads, first the reactive power is injected in a positive direction which leads to ROCOF variation in a positive direction. When ROCOF is increasing in a positive direction, the controller identifies and injects the reactive power in a negative direction. Now the ROCOF decreases in negative direction and islanding is detected. For inductive loads, first the reactive power is injected in negative direction which leads to ROCOF variation in a negative direction. When ROCOF is decreasing in negative direction, the controller identifies and injects the reactive power in a positive direction. Now the ROCOF increases in a positive direction and islanding is detected.

\section{REFERENCES}

[1] Yuan Kang Wu, Jhih-Hao Lin "Standards and guidelines for grid-connected photovoltaic generation systems: a review and comparison", IEEE Transactions on industry Applications, Vol. 53, No: 4, pp. 3205 - 3216, 2017.

[2] Yu Zheng, Zhao Yang Dong, Ke Meng, Hongming Yang, Mingyong Lai "Multi objective distributed wind generation planning in an unbalanced distribution system", CSEE Journal of Power and Energy Systems, Vol. 3, No. 2, pp. 186 - 195, 2017.

[3] IEEE application guide for IEEE Std 1547 (TM) IEEE standard for interconnecting distributed resources with electric power systems, IEEE Std 1547.2, 2008-2009, pp. 1-217.

[4] UL1741 standard for safety for static converters and charge controllers for use in photovoltaic power systems, Underwriters Laboratories, 2001.

[5] Ashok Bindra "A unified interface for integrating renewable energy sources with the smart grid", IEEE Power Electronics Magazine, Vol. 3, No. 4, pp. 4-6, 2016.

[6] Ch. Rami Reddy, K. Harinadha Reddy “An Efficient Passive Islanding Detection Method for Integrated DG System with Zero NDZ”, International Journal of Renewable Energy Research, vol:8, issue: 4, pp: 1994-2002, 2018.

[7] Priyanka Paliwal, N.P. Patidar, R.K. Nema "Planning of grid integrated distributed generators a review of technology, objectives and techniques", Renewable and Sustainable Energy reviews, Vol. 40, pp. 557-570, 2014.

[8] Ch. Rami Reddy, K. Harinadha Reddy "Islanding detection for inverter based distributed generation with Low frequency current harmonic injection through Q controller and ROCOF analysis", Journal of electrical systems, volume: 14, issue: 02, pp: 179-191, 2018.

[9] Ke Jia, H. Wei, Tianshu Bi, David Thomas "An islanding detection method for multi DG systems based on high frequency impedance estimation”, IEEE Transactions on sustainable energy, Vol. 8, No. 7, pp. 74 - 83, 2017.

[10] Suman Murugesan, V.k. Murali, S. Arul Daniel "Hybrid analyzing technique for active islanding detection based on d axis current injection", IEEE Systems Journal, No. 99, pp. 1-10, 2017.

[11] Zhongwei Guo "A harmonic current injection control scheme for active islanding detection of grid connected inverters", IEEE International Telecommunications Energy Conference, Osaka, Japan, pp. 1 - 5, 2015.

[12] Snehamoy Dhar, Sheetal Chandak, M H Naeem "Harmonic profile injection based active islanding detection for PV-VSC based grid", IEEE Power Communication and Information Technology Conference, pp. 489 - 496, 2015.

[13] K. V. Siva Reddy, SK. Moulali, K. Harinadha Reddy, Ch. Rami Reddy, B. V. Rajanna, G. Venkateswarlu, Ch. Amarendra "Resonance Propagation and Elimination in Integrated and Islanded Micro grids", International journal of power electronics and drive system, volume: 09, issue: 03, pp. 1445-1456, 2018.

[14] Xiaolong Chen, Yongli Li: An islanding detection method for inverter based distributed generators based on the reactive power disturbance, IEEE Transactions on Power Electronics, Vol. 31, No. 5, 2016, pp. 3559 - 3574.

[15] David Reigosa, Fernando Briz, Cristian Blanco, Pablo García "Active islanding detection for multiple parallel connected inverter based distributed generators using high frequency signal injection", IEEE Energy Conversion Congress and Exposition, Raleigh, NC, USA, September 2012, pp. 2719- 2726.

[16] K. Suresh, P. Anusha, Sk. Najma, B. I. Rajkumar, Ch. Rami Reddy, B. Prasanna Lakshmi "A passive islanding detection method for hybrid distributed generation system under balanced islanding", Indonesian Journal of Electrical Engineering and Computer Science, Vol. 14, No. 1, pp. 9 19, 2019.

[17] Zhihong.Y., Kolwalkar A., Zhang Y "Evaluation of anti islanding schemes based on nondetection zone concept", IEEE Transactions on Power Electronics, Vol.19, 2004, pp. 1171-1176.

[18] I. M. Isa, H. Mohamad, Z. M. Yasin "Evaluation on non detection zone of passive islanding detection techniques for synchronous distributed generation”, IEEE Symposium on Computer Applications \& Industrial Electronics, 2015, pp. $100-104$.

[19] Narayanan K., Shahbaz Ahmed Siddiqui, Manoj Fozdar "Hybrid islanding detection method and priority based load shedding for distribution networks in the presence of DG units", IET Generation, Transmission \& Distribution, Vol. 11, No. 3, 2017, pp. 586 - 595.

[20] Riyasat Azim, Fangxing Li, Xiayang Zhao "A hybrid islanding detection technique for inverter based distributed generations", IEEE Electrical Power and Energy Conference, London, Ontario, Canada, pp. 239 - 243, 2015.

[21] Mahdiyeh Khodaparastan, Hesan Vahedi, Farid Khazaeli, Hashem Oraee "A novel hybrid islanding detection method for inverter based dgs using SFS and ROCOF", IEEE Transactions on Power Delivery, Vol. 32, No. 5, pp. $2162-2170,2017$. 
[22] Reddy, C.R. \& Reddy, K.H. Journal of Electrical engineering and Technology (2019). https://doi.org/10.1007/s42835-018-00073-x

[23] Chung Chuan Hou "A hybrid islanding detection for distributed generation systems using pulse current injection", IEEE International Symposium on Industrial Electronics, Hangzhou, China, May 2012, pp. 1554 - 1559.

[24] Ch Rami Reddy, K.H. Reddy, K.V.S. Reddy "Recognition of Islanding Data for Multiple Distributed Generation Systems with ROCOF Shore Up Analysis”, Smart Intelligent Computing and Applications, pp: 547-558, 2019.

[25] Bikiran Guha, Rami J. Haddad, Youakim Kalaani "A passive islanding detection approach for inverter based distributed generation using rate of change of frequency analysis", South East Conference, pp. 1 - 6, 2015.

[26] Sittichai Keawthai, Sakorn nagam "Simplified active power and reactive power control with MPPT and islanding detection for three phase grid connected photo voltaic inverters", International Conference on Electrical Engineering/Electronics Computer Telecommunications and Information Technology, Hua hin, Thailand, pp. $1-6,2015$.

[27] Hajir Pourbabak, Ahad Kazemi "Islanding detection method based on a new approach to voltage phase angle of constant power inverters", IET Generation, Transmission \& Distribution, Vol. 10, No. 5, pp. 1190 - 1198, 2016.

[28] S. K. Salman, D. J. King, G. Weller "New loss of mains detection algorithm for embedded generation using rate of change of voltage and changes in power factors", Seventh International Conference on Developments in Power System Protection, Amsterdam, Netherlands, April 2001, pp. 82 - 85.

[29] Gang Wang, Shuangjiang Yu, Qifu Cheng, Xiaotong Zhang, Dazhong Ma, Siyuan Guo, Chengzhe Liu, Chuntao Yu "An islanding detection method based on adaptive reactive power disturbance", Chinese Automation Congress, Jinan, China, pp. $6268-6273,2017$.

[30] Zeineldin, H.H., Kirtley "Performance of the OVP/UVP and OFP/UFP method with voltage and frequency dependent loads", IEEE Transactions on Power Delivery, Vol. 24, pp. 772-778, 2009.

[31] Yan Li, Peng Zhang, Wenyuan Li, Joseph N. Debs, David A. Ferrante, Donald J. Kane, Samuel N. Woolard, Roderick Kalbfleisch, Kenneth B. Bowes, Andrew Kasznay "Non detection zone analytics for unintentional islanding in distribution grid integrated with distributed energy resources", IEEE Transactions on Sustainable Energy, pp. 1 - 10, 2018.

[32] Sung. J., Kwang Ho "An islanding detection method for distributed generations using voltage unbalance and total harmonic distortion of current, IEEE Transactions on Power Delivery, Vol.19, pp. 745-752, 2004.

[33] Vaclav Muzik, Vladimir Vajnar "Frequency and voltage stability assessment of a power system during emergency service states", IEEE Conference of Russian Young Researchers in Electrical and Electronic Engineering, Moscow, Russia, January/February 2018, pp. 708 - 711.

[34] Ch. Rami Reddy, K. Harinadha Reddy "Islanding detection method for inverter based distributed generation based on combined changes of ROCOAP and ROCORP", International Journal of Pure and Applied Mathematics, Vol. 117, No. 19, pp. 433-440, and 2017.

[35] Ch. Rami Reddy, K. Harinadha Reddy "A Passive Islanding Detection method for Neutral point clamped Multilevel Inverter based Distributed Generation using Rate of Change of Frequency Analysis" International journal of electrical and computer engineering, volume: 08, issue: 04, pp:1967-1976, 2018 